\title{
1 A framework for modelling local production systems with techno-ecological interactions
}

2 Elias Martinez-Hernandez ${ }^{1,2}$, Melissa Yuling Leung Pah Hang ${ }^{2}$, Matthew Leach ${ }^{2}$, Aidong

$4 \quad{ }^{1}$ Department of Engineering Science, University of Oxford, Oxford, OX1 3PJ, UK

$5 \quad{ }^{2}$ Centre for Environmental Strategy, University of Surrey, Guildford, GU2 7XH, UK

\section{Address correspondence to:}

$7 \quad *$ Dr. Aidong Yang, e-mail: aidong.yang@eng.ox.ac.uk

8 Nomenclature

$9 \quad A_{h} \quad$ Harvested heathland area

$10 \quad B \quad$ Standing biomass

$11 C_{(s+b)}$ Total carbon capture rate

$12 C_{\text {soil }} \quad$ Carbon stock in soil

$13 D_{e} \quad$ Demand of reference

$14 \quad F \quad$ Flow

$15 f_{A G, S} \quad$ Fraction of biomass growth allocated to above-ground biomass of species $s$

$16 F_{\text {cons }}$ Resource consumption rates of processes

$17 f_{\text {cut }} \quad$ Annual cut fraction

$18 \quad F_{d e p}^{N} \quad$ Atmospheric nitrogen deposition

$19 F_{e} \quad$ Energy supplied from bioenergy production system

$20 \quad F_{e l} \quad$ Net electricity production

$21 F_{\text {gen }} \quad$ Resource generation rates of processes

$22 F_{\text {growth,s }}$ Biomass growth rate of species $S$

$23 F_{\text {harv }, s} \quad$ Harvest rate of species $s$

$24 \quad F_{\text {in }} \quad$ Input flows to system

$25 F_{i n}^{e p, b} \quad$ Input biomass flow to energy production

$26 F_{\text {in }}{ }^{h, f}$ Input fertilizer flow to heathland

$27 \quad F_{i n}{ }^{i, j} \quad j^{\text {th }}$ inlet flow of component $i$

$28 \quad F_{\text {out }} \quad$ Output flows from system 
$29 F_{\text {out }}{ }^{e p, f}$ Outlet fertilizer flow from energy production

$30 F_{\text {out }}{ }^{h, b}$ Outlet biomass flow from heathland

$31 F_{\text {out }}^{k, m} \quad m^{\text {th }}$ outlet flow of component $k$

$32 F_{\text {mort }, s} \quad$ Mortality or litter production rate of the species $s$

$33 \quad F_{p} \quad$ Generation or consumption rates of processes

$34 H_{\text {biogas }}$ Heating value of biogas

$35 H_{w b} \quad$ Heating value of woody biomass

36 HP Human Population

$37 \quad \mathrm{I}_{\mathrm{s}} \quad$ State indicator

38 If Flow indicator

$39 \quad \mathrm{I}_{\text {sf }} \quad$ State-flow indicator

$40 \quad k \quad$ Growth rate constant

$41 k_{\text {biogas }}$ Biogas yield from input biomass flow

$42 \quad k_{\text {lossC }} \quad$ Soil C loss rate constant

$43 \quad k_{m, s} \quad$ Mortality or litter production rate constant of species $s$

$44 \quad k_{p} \quad$ Process rate constant

$45 \quad L \quad$ Competition function of the Lotka-Volterrra form

$46 \quad M_{s} \quad$ Mortality rate of species $s$

$47 \mathrm{~N} \quad$ Nitrogen

48 S State variable

49 s1 Heather

50 s2 Grass

$51 t \quad$ Time

$52 y_{C} \quad$ Carbon fraction in biomass

$53 y_{N, S} \quad$ Nitrogen content in biomass of species $S$

$54 y_{\text {soft }, s} \quad$ Soft fraction in biomass from species $s$

$55 \eta_{e l}^{\text {biogas }}$ Electricity efficiency of CHP plant using biogas

$56 \quad \eta_{e l}^{w b} \quad$ Electrical efficiency of CHP using woody biomass

$57 \quad \delta_{e} \quad$ Demand satisfaction indicator

\section{Keywords}

59 localized production, techno-ecological system, bioenergy, modelling, symbiosis 


\section{$<$ heading level 1> Summary}

At the local scale, interconnected production, consumption, waste management and other man-made technological components interact with local ecosystem components to form a local production system. The purpose of this work is to develop a framework for the conceptual characterization and mathematical modelling of a local production system to support the assessment of process and component options that potentially create symbiosis between industry and ecosystem. This framework has been applied to a case study to assess options for the establishment of a local energy production system that involves a heathland ecosystem, bioenergy production and wastewater treatment. We found that the framework is useful to analyze the two-way interactions between these components in order to obtain insight into the behavior and performance of the bioenergy production system. In particular, the framework enables exploring the levels of the ecosystem states that allow continuous provisioning of resources in order to establish a sustainable techno-ecological system.

\section{$<$ heading level 1 $>$ Introduction}

The increasing world population and the subsequent rise in energy and materials consumption are leading to resource constraints. At the same time, ecosystem functions are being affected due to the release of pollutants by human activities, threatening the continuous supply of ecosystem goods and services (MEA 2005). This drives the need for considering new ways to meet human needs in a more sustainable manner. One possible pathway is to shift the supply of basic human needs from large scale centralized production systems to localized production systems. Localized production creates opportunities to integrate ecosystem and technological components to satisfy the needs of the local population whilst observing the local environmental constraints, and to foster symbiosis between different processes. 

of alternative forms of economic development (Curtis 2003; Johansson et al. 2005). The UK's Royal Academy of Engineering identifies the positive potential for localized energy and water supply particularly with respect to resilience in the context of climate change adaptation (RAE 2011). This is also in line with the Millennium Ecosystem Assessment that shows that the "adapting mosaic" scenario is the only one in which the state of all ecosystem services is expected to be enhanced by focusing on local management strategies (MEA 2005).

Localized production is closely related to existing work in industrial ecology. Under the broad theme of industrial symbiosis (Chertow and Ehrenfeld 2012), supply of water (Liang et al. 2011) and energy (Hiete et al. 2012) and waste treatment (Eckelman et al. 2014) have been studied for eco-industrial parks. Desrochers (2001) has analyzed the exchange of wastes, by-products and energy among closely situated firms and the incentives that promote linkages at both the local and interregional levels. Fröhling et al. (2013) have proposed a material-flow based approach for the analysis of the connections between production and recycling networks. Studies on industrial ecosystems using network theory suggest that higher structural cyclicity has the potential for a higher maximum thermal efficiency (Layton et al. 2012) and that increasing connectance between components might lead to higher resource efficiency yet possibly at the expense of stability and environmental performance

102 (Hardy and Graedel 2002). The reason for this might be that, although life cycle assessment 103 (LCA) has been applied to study industrial symbioses (Mattila et al. 2012), connections and interactions with two important parts of the life cycle are often missing: 1) the ecosystem, as the ultimate resource provider, and 2) final consumption by population where resources are

106 degraded to low quality. In particular, the importance of supporting decision making by 107 considering techno-ecological interactions has been highlighted by several authors (Urban et al. 2010; Urban and Bakshi 2013; Song and Frostell 2012). 

local ecosystems, production and consumption components in order to devise ways to meet

111 the needs of the local population whilst maintaining the ecosystem capacities that can keep

112 the local production system operating in a sustainable manner. The framework consists of

113 conceptual and mathematical characterization of a local system and is illustrated by a case

114 study comprising a heathland ecosystem, sewage water treatment and bioenergy production.

\section{$<$ heading level $1>$ The concept of a localized production and consumption system}

Within the wide spectrum of possible geographical scales for organizing production

117 activities, the term "local" is undoubtedly relative. Nevertheless, it generally holds that the

118 scope of a local system should be one which emphasizes the co-location of resource

119 extraction, production and consumption and which enables the account of the affected ecosystems at a detailed level. This can often correspond to some of the existing, lower levels of public governance (e.g. a town, city, or county) where sustainability-embracing decisions may be pursued based on sufficient "local” details. 1, consisting of (i) the natural environment and the associated ecological processes and (ii) the human-created components and the associated production and consumption processes, all within a specific geographical boundary. The basic needs of local population (nutrition, thermal comfort, hydration, etc.) are the drivers of a local production system. Such needs are met through energy and material flows (food, fuel, water) generated from the production processes. These production processes make use of locally available (often renewable) resources provided by ecological processes in the local environment. In turn, the production processes and

131 consumption affect the local environment through the discharge of pollutants and wastes.

132 External resources will be needed as incoming flows, as local environment cannot provide all 
133 the types and amount of resources, and some excess products (e.g. surplus electricity) or

134 pollutants and wastes (e.g. $\mathrm{CO}_{2}$ emissions) may be exported as outgoing flows. This diagram

135 emphasizes that it is through the ecological, production and consumption processes that we try

136 to satisfy the basic human needs. How to devise and study the wise integrations between them

137 in a systematic way is addressed in this article by proposing and illustrating a conceptual and

138 quantitative modelling framework.

From the perspective of industrial ecology, the present research envisages localized

140 production activities in the form of a synergetic and evolving system in which heterogeneous

141 production facilities are integrated to potentially achieve a high degree of resource efficiency

142 and resilience, consequently enhancing the (collective) economic viability whilst maintaining

143 harmony with the ecosystem. Besides, a local production system will interact with peers in

144 neighboring localities with different sets of resource availability and population needs, and

145 also exchange with centralized large-scale production and distribution infrastructures, which

146 are either desirable elements in the appropriate economic balance between centralized and

147 localized systems or merely legacies in the course of shifting towards localized production.

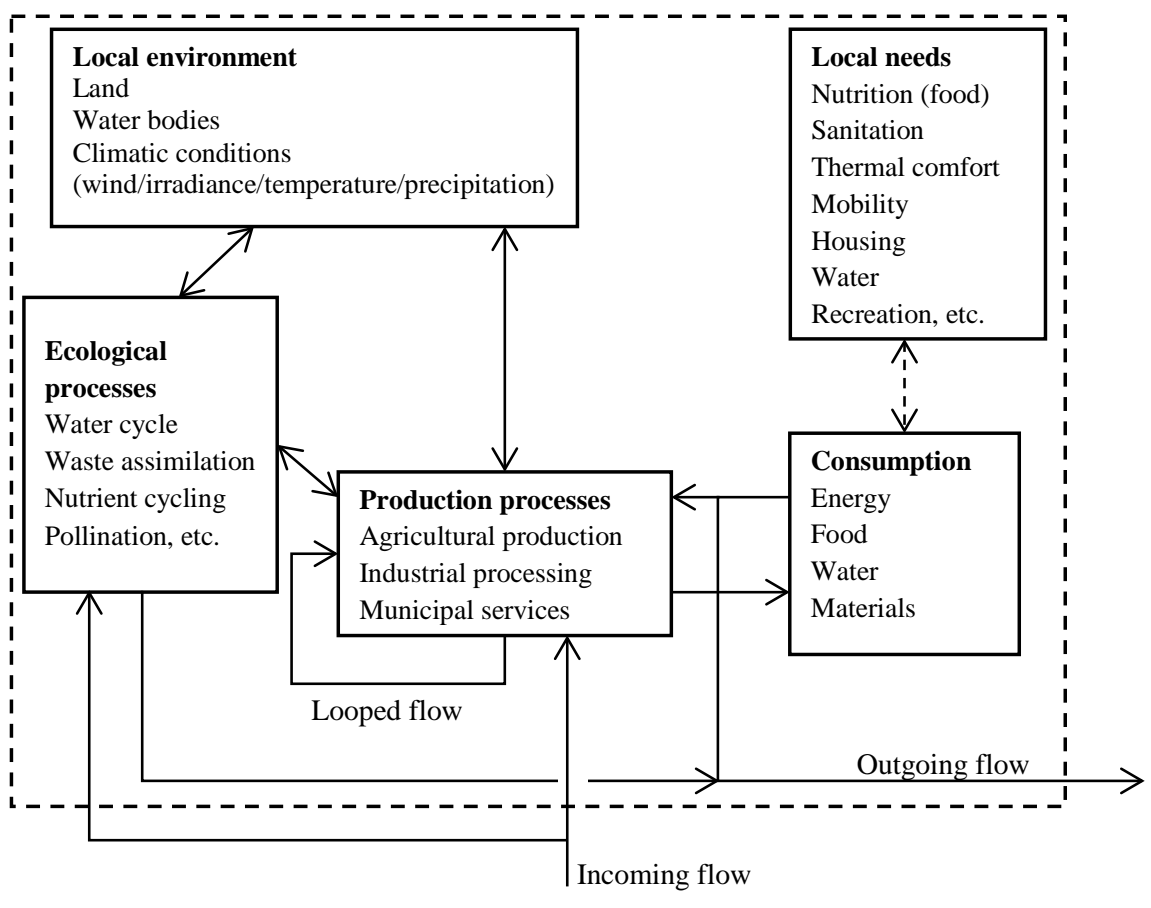


149 Figure 1. The concept of localized production, consumption and ecological processes. $<$ heading level $1>$ Conceptual characterization of local production systems The first step is to provide a systematic and common conceptual framework. To this

152 end, the various blocks and their interrelations in figure 1 can be represented as in figure 2,

153 where the set of common concepts are linked through subclass (i.e. one concept is a subclass

154 or special case of another concept), composition (i.e. an object depicted by one concept forms 155 part of an object by another concept), or general association (e.g. a process affects a state or a

156 flow rate). This conceptual model is proposed to facilitate the identification and

157 characterization of key components and their connections, which may form a basis for further

158 mathematical modelling among other possible uses. The conceptual depiction of the system is

159 organized into different views, namely structural, behavioral, functional and performance. In

160 addition, a physical view is needed to address the physical nature of components, flows,

161 processes and states. 


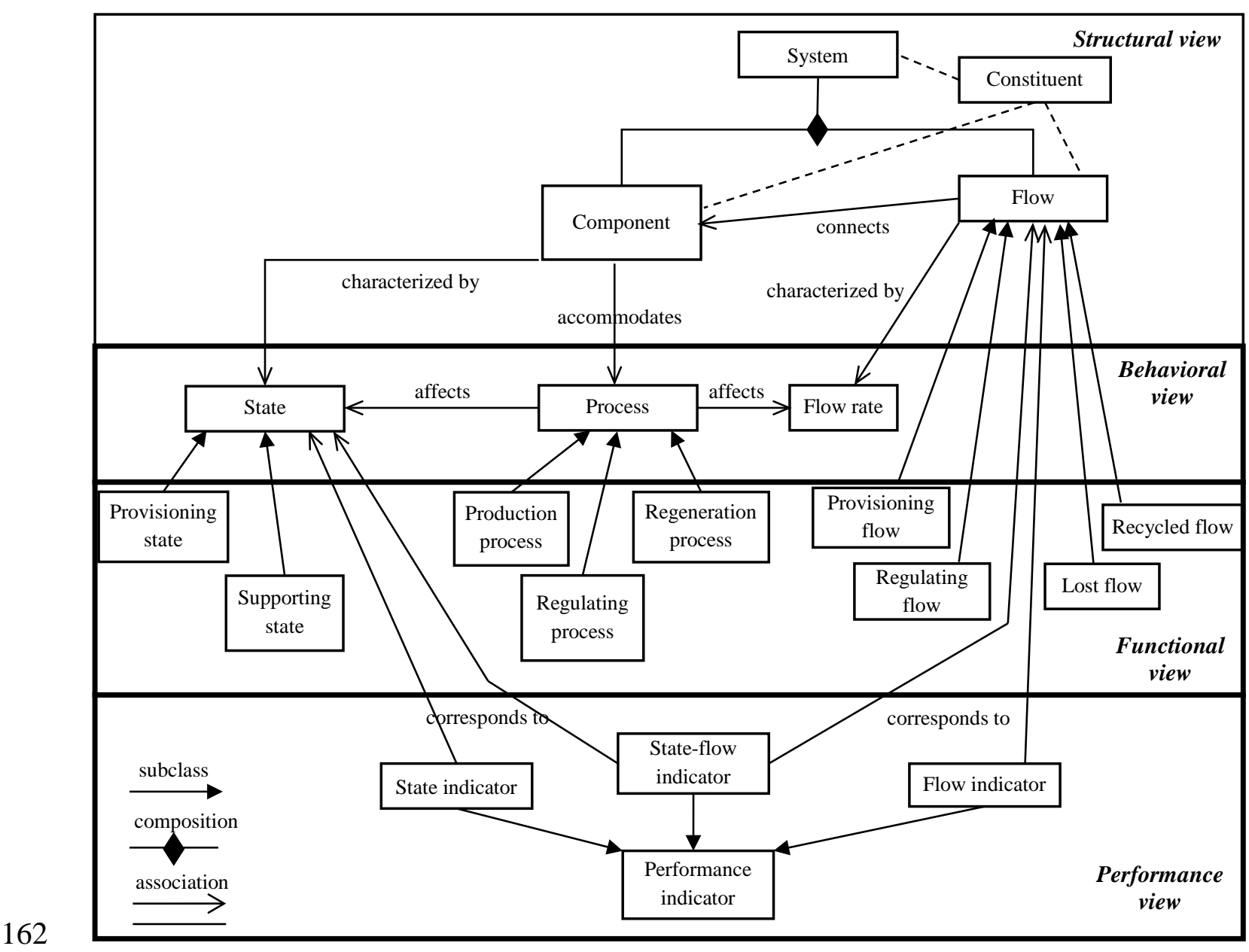

163 Figure 2. Conceptual model for characterization of localized production systems. $<$ heading level $2>$ Structural view In the structural view, the system is composed of components and flows. A

166 component is a subsystem, which is connected with other components via flows. The content

167 of a component or a flow is represented by the concept of constituent, which describes the

168 basic ingredients of the system. Depending on the physical nature of a component or a flow,

169 its constituents could include certain type(s) of material, energy, physical objects, biological

170 entities, etc. Components are characterized by states and host processes, as depicted below by

171 the behavioral view. It generally holds that a system or a system component can be

172 decomposed hierarchically (a component may be composed of several components and flows

173 from a lower level). 
Processes and states are the key concepts for depicting the behavior of a system. A

176 process may change flows by varying their condition or nature. It may also modify the flow

177 rates and the states of the components. The term state refers to the state variables that

describe the attributes or conditions of the components. Thus, the behavior of the system is

determined by the dynamics of the processes and the extent of the modifications on flow rates

and states. By examining the processes, the current and future states of the components can

be analyzed, and subsequently the ability or capacity of the system to maintain the provision services for meeting local needs within ecological constraints can be determined. The latter aspect is further unfolded by the functional view.

\section{$<$ heading level 2> Functional view}

If one takes a human-centric, utilitarian view on top of the abstract concepts of a system's structure and behavior as presented above, a functional view can be introduced by further classifying states, processes and flows into subclasses according to their direct or indirect roles in providing products and services for meeting human demands, similar to the approach adopted by the MEA (2005) for classifying ecosystem services. Specifically, states can be classified into provisioning and supporting states. A provisioning state refers to the capacity of the system to meet a certain demand; for example, the wheat productivity of a farmed land (as the capacity for providing a flow of wheat) or the forest coverage of an area

193 (as the capacity for meeting cultural/recreational needs). A supporting state, often manifested as a stock, is one required to maintain one or more provisioning states (for example, a certain level of soil depth or nutrient content required to maintain the level of wheat productivity). Due to the roles of the supporting states, these states may impose limits to a local production system. As the system is dynamic, it is important to assess the changes 
in these supporting states caused by processes and flows and the corresponding changes in the provisioning states which may be enhanced or reduced as the system evolves with time.

A similar functional classification can be made to the processes according to their roles in changing the flows and states. Here, processes are classified as production, regulating, and re-generation processes. Flows are classified as provisioning, regulating, recycled and lost flows. The provisioning flows meet the local needs for products or services and are produced by production processes. The production processes transform provisioning flows into other provisioning flows (of the same or different form, with the same or different constituents, from/to the same or different component) and into degraded flows. Degraded flows are a subclass of flow that be lost or appear as intermediate flows to be further processed by regeneration or regulating processes (e.g. wastewater treatment).

Regeneration processes transform a degraded flow of constituents into a form that can be

210 returned to the production processes as a recycled flow, or to a supporting state in the form of a stock. Regulating processes do not produce any direct provisioning flow but support the regeneration processes and the maintenance of supporting states. They act as buffering mechanisms in the system to alleviate any burden mainly imposed by the production

214 processes and the resulting pollutant emissions. Regulating processes may generate flows

215 necessary for regulation. Such flows are called regulating flows and examples include litter nutrients mineralized in soil or direct fertilizer application, as these are flows that can help to balance deficit of nutrients thus regulating crop yields. Emitted flows might damage the ecosystem if they are discharged at a flow rate that is higher than the assimilation rate of the regulating processes. Emitted flows could also be transported and exported to other systems and therefore can be classified as lost flows (this means lost by the local system, but might be gained by any other system). Other lost flows are those diverted by natural or technological 
components and transported outside of the local system boundary (e.g. rainwater discharged into a river).

\section{<heading level 2> Performance view}

The functioning of a local production system can be evaluated quantitatively by means of a set of specific performance indicators. From the above discussions, quantification of a system is primarily by its states of components and rates of flows. Accordingly, a performance indicator may be defined based on one or several states (termed a state indicator), one or several flows (termed a flow indicator), or a combination of state(s) and flow(s) (termed as a state-flow indicator). An example of state indicator for a vegetation ecosystem is the carbon or nitrogen stock in the soil (each being a state), or the ratio between these two states. A flow indicator can relate for example the rate of aquifer recharge and the aquifer extraction rate (both as a flow rate). A state flow indicator can relate the rate of water extraction (a flow rate) and the water storage in an aquifer at certain point in time (a state).

\section{$<$ heading level 2> Physical view}

In parallel with the functional view and the performance view, the physical view classifies the rather abstract concepts of a system's structure and behavior according to their physical natures, which is closely related to the mathematical modelling of the system's behavior as the latter is typically based on physical principles. In this work, only a high-level classification of system components is presented via three major types of component which typically exist in a local system: ecosystem, technological and human being.

The ecosystem component is made up of natural environments such as a forest, a lake or a wetland and are classified into biotic and abiotic components. Within abiotic 
components, land includes mainly soil as source/sink of nutrients such as nitrogen and carbon; and air focuses on the material and energy flows exchanged with the other components, especially water, pollutant and solar radiation flows. The man-made technological components are artifacts resulting from human activities such as a power plant or a processing facility. Such components can be classified into building, equipment and machinery, and infrastructure which form the physical basis for industrial, agricultural, commercial, municipal and other civil operations. For example, energy production requires equipment (such as tanks, reactors, turbines), buildings for operation and management, and infrastructure (such as storage space and piping). organizations. Individuals and families or households are the units for understanding consumption. Individuals and families further form communities, where different patterns of consumption emerge, and organizations (such as companies, governments, NGOs), which devise and/or adopt policies, strategies or regulations pertaining to production and consumption. Human components are where most of the consumption takes place, setting the flows rates of products required to meet the needs of the local population.

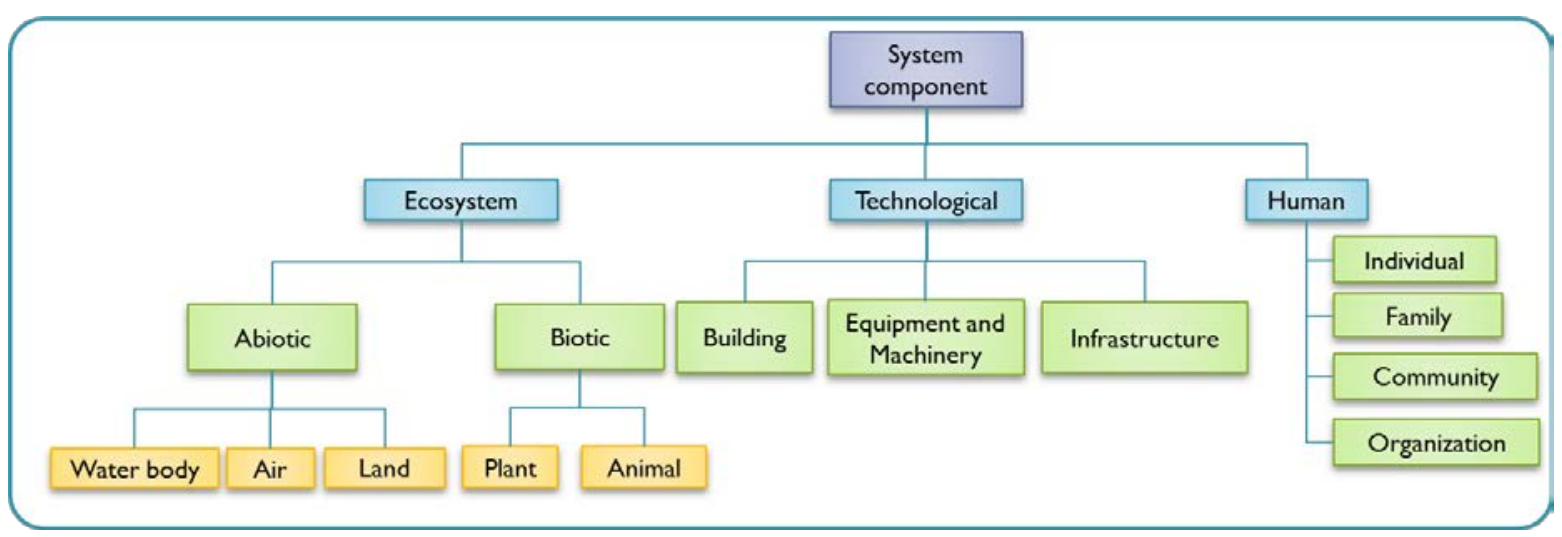

Figure 3. Components in the physical view. 

of modelling is required to predict or estimate the system's behavior and performance.

\section{$<$ heading level 2> Behavioral modeling} connectivity equations between components to model flow exchanges. A generic technoecological process model can be formulated following a system dynamics (SD) approach, similar to other parallel approaches for structured model construction, such as the one

271 adopted by chemical engineering (Kröner et al. 1990; Morbach et al. 2007). The generic rate

272 of change of a state (stock) variable $S$ within a system component can be expressed as:

$$
\frac{d S}{d t}=F_{\text {in }}-F_{\text {out }}-F_{\text {cons }}+F_{\text {gen }}
$$

273 where $\frac{d S}{d t}$ is the accumulation rate of the resource characterising the state (for example, nitrogen 274 in soil)

$275 F_{\text {in }}$ and $F_{\text {out }}$ are input and output flows to and from the system, respectively

$276 F_{\text {cons }}$ and $F_{\text {gen }}$ are the resource consumption and generation rates of processes within a 277 component's boundary, respectively

278 Constitutive equations representing the rates of flows, consumption and generation can be 279 introduced, depending on the physical nature of the processes involved. These equations for 280 generation or consumption rates of a process can be expressed as a function of a process rate 281 constant $k_{p}$, a state variable $S$, and/or a flow $F$.

$$
F_{p}=f\left(k_{p}, S, F\right)
$$


In addition to balance and constitutive equations, some connectivity equations

modeling the structural relationship between system components are required. A generic connectivity equation can be expressed as shown in equation 3.

$$
F_{\text {in }}{ }^{i, j}=F_{\text {out }}{ }^{k, m}
$$

286 where $F_{i n}{ }^{i, j}$ stands for the $j^{\text {th }}$ inlet flow of component $i$, and $F_{\text {out }}{ }^{k, m}$ the $m^{\text {th }}$ outlet flow of 287 component $k$. of influence of the various process rates.

A performance indicator is modeled as a function of one or more states, a function of one or more flows, or a function of both:

$$
\begin{gathered}
I_{s}=f\left(S_{1}, S_{2}, \ldots, S_{i, \ldots,} S_{n}\right) \\
I_{f}=h\left(F_{1}, F_{2}, \ldots, F_{j, \ldots,} F_{m}\right) \\
I_{s f}=g\left(S_{1}, S_{2}, \ldots, S_{i, \ldots,} S_{n}, F_{1}, F_{2}, \ldots, F_{j, \ldots,} F_{m}\right)
\end{gathered}
$$

where $I_{s}$, $I_{f}$, and $I_{s f}$ are a state indicator, a flow indicator, and a state-flow indicator, respectively, and $S_{i}$ and $F_{j}$ represent a state and a flow, respectively.

Figure 4 synthesizes the overall system characterization framework. In a particular application the system characterization starts with defining the temporal and spatial scopes. Then, structural characterization follows to identify the components to be included in the analysis according to the objective of the study. With a specific set of performance indicators in mind, states and flows are subsequently identified, followed by the identification and 
300 characterization of the processes affecting the important states and flows. It is particularly

301 important at this point to identify those processes and flows leading to key connections that

302 can potentially enhance (or otherwise) the system in terms of resource efficiency, ecosystem

303 health or other performance indicators. Examples of such connections include looping and

304 matching between sources and demands through recycling, reuse and regeneration of resources.

305 Next steps are mathematical modeling, collection of input data and setting parameters before 306 proceeding to calculations and assessment.

307

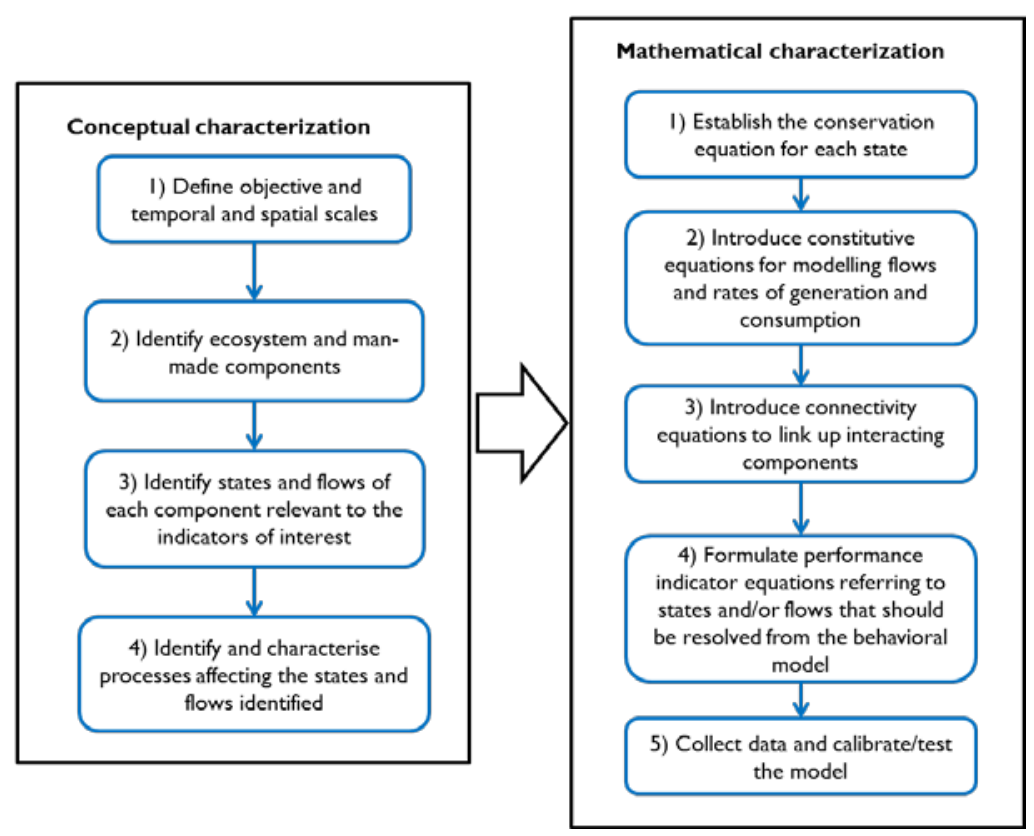

308 Figure 4. Overall framework for modelling local production systems with techno-ecological

309 interactions

313 (Whitehill and Bordon 2012) was undertaken, which addresses a system consisting of

314 bioenergy production from heathland biomass (Woodcock and Stephens 2012) and sewage 
315 sludge as locally available resources for meeting local heat and electricity demands, as shown

316 in figure 5.

Step 1. The objective was to assess biomass resource availability and the effect of the integration between energy production and the ecosystem. The spatial scope is that of the Whitehill and Bordon eco-town including its heathlands areas. Heathlands are an important ecosystem in the UK and Europe dominated by heather species (e.g. Calluna vulgaris), coexisting mainly with grass species (e.g. Deschampsia flexuosa). The temporal scope is a management timeline of 50 years. The final performance indicators of interest are a) the demand satisfaction rate as the percentage of energy that can be supplied to the eco-town whilst maintaining the heathland ecosystem, and b) the carbon storage in the ecosystem. Although these are reasonable indicator choices given the focus on the provision of energy, other important factors such as the structural changes of the eco-industrial network and ecosystem patterns that influence the functioning of the overall system should be considered in future work for a better evaluation of environmental sustainability. components include energy production and sewage treatment and an aggregated component including residential, commercial and industrial buildings. determine the amount of bioenergy production, the relevant flows are the biomass harvest rate and the nitrogen inputs (deposition from air and fertilization by nitrogen recycling). To ensure the heathland is maintained, the amount of standing biomass and nitrogen in soil, as key states, need to be tracked. 
Processes in components outside the boundary in figure 5 (air component and water body processes, states and flows are described as follows.

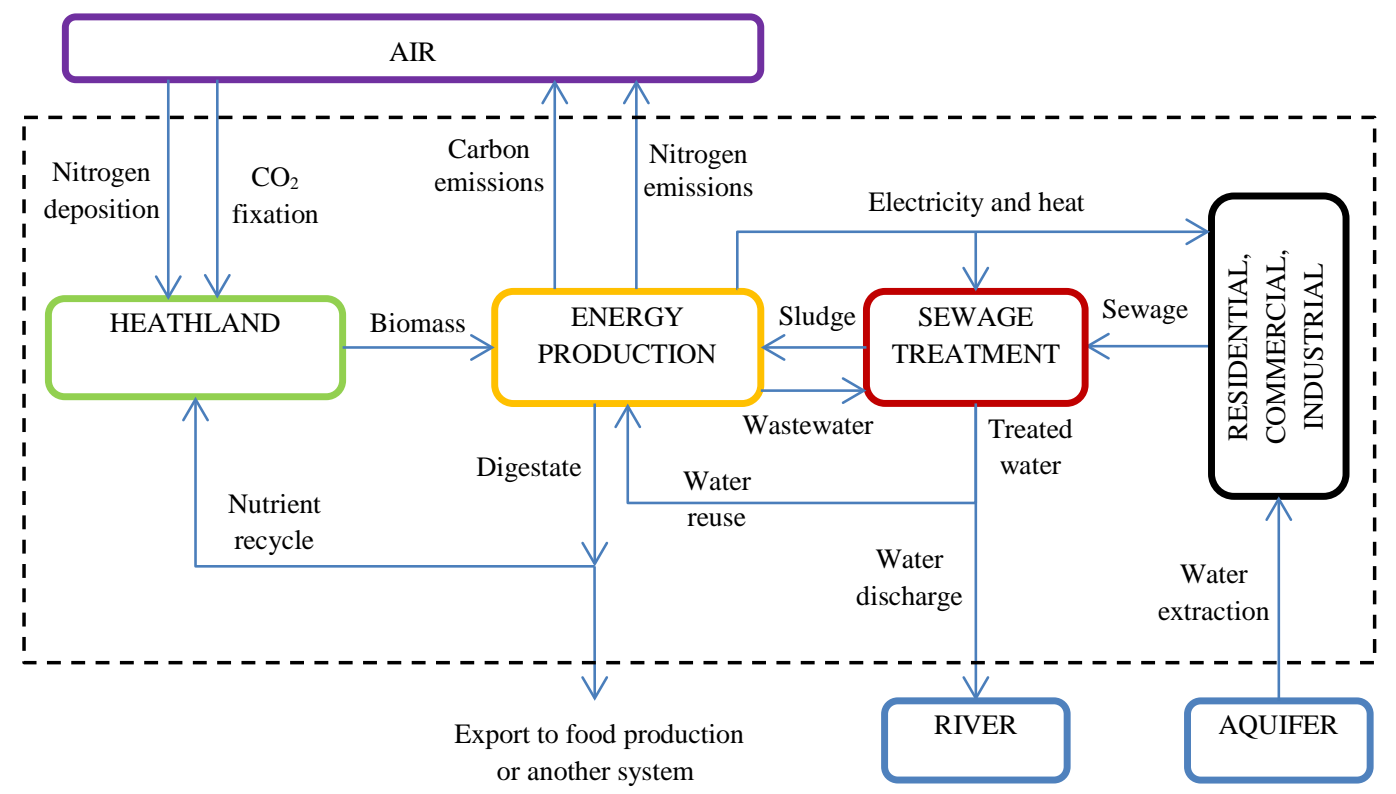

344 Figure 5. The local production system as analyzed in the case study. compete for land and nutrients (Heil and Bobbink 1993; Bakema et al. 1994). Although other nutrients are needed for plant growth, this work focuses on nitrogen due to its distinct importance to maintain heathland ecosystems. Standing biomass of heather and grass and the nitrogen stock in the soil are the main states in the heathland component. Such states are affected by the processes of biomass growth, mortality and harvesting. Growth rate is affected by nitrogen availability from atmospheric nitrogen deposition, mineralization of

352 litter in heathland soil, and nutrient recycling from the energy production component. At this 353 point, a symbiotic relation can be created whereby the (necessary) removal of nitrogen from 
Table 1 System conceptual characterization of the bioenergy production system analyzed in

the case study

\begin{tabular}{|c|c|c|c|c|}
\hline Component (type) & States (type) & Processes (type) & $\begin{array}{l}\text { Input flows to } \\
\text { component (type) }\end{array}$ & $\begin{array}{l}\text { Output flows } \\
\text { from component } \\
\text { (type) }\end{array}$ \\
\hline $\begin{array}{l}\text { Air (ecosystem } \\
\text { abiotic component) }\end{array}$ & - & - & $\begin{array}{l}\text { - Nitrogen emissions } \\
\text { (lost flow) } \\
\text { - COO } \mathbf{O}_{2} \text { emissions } \\
\text { (recycled flow) }\end{array}$ & $\begin{array}{l}\text { - Nitrogen } \\
\text { deposition } \\
\text { (regulating flow) } \\
\text { - CO2 fixation } \\
\text { (regulating flow) }\end{array}$ \\
\hline $\begin{array}{l}\text { Heather and grass } \\
\text { (ecosystem biotic } \\
\text { component) }\end{array}$ & $\begin{array}{l}\text { Standing } \\
\text { heather and } \\
\text { grass biomass } \\
\text { (supporting } \\
\text { state) }\end{array}$ & $\begin{array}{l}\text { - Biomass growth } \\
\text { (production process) } \\
\text { - Biomass mortality } \\
\text { (consumption process) }\end{array}$ & $\begin{array}{l}\cdot \mathbf{C O}_{2} \text { (regulating } \\
\text { flow) } \\
\text { - Nitrogen uptake } \\
\text { (regulating flow) }\end{array}$ & $\begin{array}{l}\text { - Nitrogen in litter } \\
\text { (regulating flow) } \\
\text { - Harvested } \\
\text { biomass } \\
\text { (provisioning flow) }\end{array}$ \\
\hline $\begin{array}{l}\text { Soil (ecosystem } \\
\text { abiotic component) }\end{array}$ & $\begin{array}{l}\text { Nitrogen stock } \\
\text { (supporting } \\
\text { state) }\end{array}$ & $\begin{array}{l}\text { Mineralization } \\
\text { (regulating process) }\end{array}$ & $\begin{array}{l}\text { - Nitrogen in litter } \\
\text { (regulating flow) } \\
\text { - Nitrogen deposition } \\
\text { (regulating flow) } \\
\text { - Fertilizer (recycled } \\
\text { flow) }\end{array}$ & $\begin{array}{l}\text { Nitrogen uptake } \\
\text { (regulating flow) }\end{array}$ \\
\hline $\begin{array}{l}\text { Energy } \\
\text { production } \\
\text { (technological } \\
\text { component) }\end{array}$ & - & $\begin{array}{l}\text { - Combined Heat and } \\
\text { Power generation } \\
\text { (production process) } \\
\text { - Anaerobic digestion } \\
\text { (production, } \\
\text { regeneration process) }\end{array}$ & $\begin{array}{l}\text { - Harvest woody } \\
\text { biomass (provisioning } \\
\text { flow) } \\
\text {-Soft biomass to } \\
\text { (provisioning flow) } \\
\text { - Sewage sludge } \\
\text { (recycled flow) }\end{array}$ & $\begin{array}{l}\text { - Carbon and } \\
\text { nitrogen emissions } \\
\text { (lost flow) } \\
\text { - Electricity } \\
\text { (provisioning flow) } \\
\text { - Heat (provisioning } \\
\text { flow) } \\
\text { - Fertilizer } \\
\text { (provisioning flow) }\end{array}$ \\
\hline $\begin{array}{l}\text { Sewage treatment } \\
\text { (technological } \\
\text { component) }\end{array}$ & - & $\begin{array}{l}\text { Sewage treatment } \\
\text { (regeneration process) }\end{array}$ & $\begin{array}{l}\text { Sewage water } \\
\text { (degraded flow) }\end{array}$ & $\begin{array}{l}\text { Sewage sludge } \\
\text { (recycled flow) } \\
\text { Treated water } \\
\text { (regenerated flow) }\end{array}$ \\
\hline $\begin{array}{l}\text { Residential, } \\
\text { commercial and } \\
\text { industrial } \\
\text { (technological } \\
\text { component) } \\
\end{array}$ & - & $\begin{array}{l}\text { Consumption } \\
\text { (consumption process) }\end{array}$ & $\begin{array}{l}\text { Electricity } \\
\text { (provisioning flow) } \\
\text { Fuel for heat } \\
\text { (provisioning flow) }\end{array}$ & $\begin{array}{l}\text { Sewage water } \\
\text { (degraded flow) }\end{array}$ \\
\hline
\end{tabular}



used as fertilizer in the heathland to increase biomass productivity, within the ecosystem limits. Here is where another techno-ecological interaction can be established between bioenergy production and ecosystem. This either contributes to the maintenance of nutrient resources within the system or can be exported as a product. Treated water from the sewage treatment process can be reused for the $\mathrm{AD}$ of soft biomass and sewage sludge. At the same time, the wastewater from the dewatering of digestate can be treated in the sewage treatment process. Furthermore, the heat and power produced from the resulting biogas can help to offset the energy demand by the water management system. This not only creates an interesting symbiosis between technological components (Layton et al. 2015; Jacobsen 2006) but also indirectly benefits the ecosystem component by saving freshwater extracted from local aquifers. To analyze the effect on water requirements and supply, water state could be also modelled, although for the purpose of illustrating the modelling framework this work has focused only on nitrogen, the main limiting resource for the heathland ecosystem.

\section{$<$ heading level 2> Mathematical modeling}

Mathematical characterization is exemplified using part of the model for the heathland ecosystem component. Heathland ecosystem models have been calibrated and tested using long-term field manipulation experiments (Power et al. 2004; Heil and Bobbink 1993; Bakema et al. 1994), and are combined here with models developed for the technological components. More detailed models and parameter values are presented elsewhere (Martinez-Hernandez et al. 2015). each of the relevant states (standing biomass and nitrogen in soil in this case). In the case of biomass state, there is no input flow but there is a generation rate due to biomass growth and 
a consumption rate due to mortality (litter production), and harvesting is the output flow. The rate of change of standing biomass $(B)$ with time can be expressed as:

$$
\frac{d B}{d t}=F_{\text {growth }}-F_{\text {mort }}-F_{\text {harv }}
$$

387 where $t$ is time, $F_{\text {harv }}$ is the harvest rate (an output flow), $F_{\text {mort }}$ is the mortality rate

388 (consumption) and $F_{\text {growth }}$ is the biomass growth rate (generation). Nitrogen $(\mathrm{N})$ availability 389 is a triggering factor for the conversion of heathland into grassland or wooded land (Bakema 390 et al. 1994; Power 2001). The tracking of accumulation of $\mathrm{N}$ in soil can also help to assess the 391 nitrogen use efficiency by the system. $\mathrm{N}$ state in soil is determined by:

$$
\frac{d N}{d t}=F_{d e p}^{N}+F_{\text {in }}{ }^{h, f}+\sum_{s}\left[\left(F_{\text {mort }, s}-F_{\text {growth }, s}\right) y_{N, s}\right]
$$

392 where $F_{i n}{ }^{h, f}$ is the inlet fertilizer to the heathland component, $F_{d e p}^{N}$ is the atmospheric 393 nitrogen deposition; $F_{\text {mort }, s}$ is the mortality or litter production rate of the species $s ; y_{N, s}$ is 394 the nitrogen content in the biomass of species $s$. consumption rates involved. For example, the growth rate of species $s\left(F_{\text {growth,s }}\right)$ is expressed in a generic form as:

$$
F_{\text {growth }, s}=\frac{d B_{s}^{\text {growth }}}{d t}=k(N) B_{s} L\left(B_{s 1}, B_{s 2}, N\right)
$$
where $k(N)$ is the growth rate constant as a function of nitrogen availability $(N)$; $L\left(B_{s 1}, B_{s 2}, N\right)$ is a competition function of the Lotka-Volterrra form in terms of heather (s1) 400 and grass (s2) biomasses and nitrogen availability (Heil and Bobbink 1993; Martinez401 Hernandez et al. 2015). 

standing biomass state:

$$
F_{\text {harv }, s}=f_{\text {cut }} B_{s}
$$

The rate of mortality of species $s$ can be expressed as:

$$
F_{\text {mort }, s}=k_{m, s} B_{s}
$$

405 where $k_{m, s}$ is the mortality or litter production rate constant of species $s$, expressed in terms of 406 standing biomass $B_{S}$.

407 The slowest processes are mainly those in the ecosystem, thus the energy production 408 and sewage treatment processes can be considered to operate in steady state. Significant 409 variations in these processes are caused by the variations in the supply of heathland or 410 sewage biomass, which in turn changes with biomass yield and local human population, 411 respectively. Thus, population dynamics were considered in order to capture such variability 412 in the sewage flow and energy demands. The model for human population (HP) in the 413 human-being component for the particular case of Whitehill and Bordon (curve fitted from 414 data reported in Whitehill and Bordon Ecotown 2012) is:

$$
H P=1917+\frac{6906}{1+e^{(829.0776-0.4099 \times \text { year })}}
$$

415 Step 3. The connectivity equations are exemplified by the synergistic connections 416 between the heathland and the bioenergy production component:

$$
\begin{aligned}
& F_{\text {in }}{ }^{e p, b}=F_{\text {out }}{ }^{h, b} \\
& F_{\text {in }}{ }^{h, f}=F_{\text {out }}{ }^{e p, f}
\end{aligned}
$$


417 where $F_{\text {in }}{ }^{e p, b}$ is the inlet biomass flow to the energy production component, $F_{\text {out }}{ }^{h, b}$ is the outlet 418 biomass flow from the heathland component, $F_{\text {out }}{ }^{e p, f}$ is the outlet fertilizer flow from the 419 energy production component that is recycled back to the heathland.

Step 4. In this step performance modelling is carried out by developing indicator equations in terms of the states or flows from the behavioral modelling. The indicators of interest are 1) for the case of the technological component, the energy demand satisfaction rate and 2) for the case of the ecosystem component, the level of carbon capture. These indicators depend on the biomass harvest flow rate, which in turn depends on the solution for the state variable of biomass in the heathland. The demand satisfaction rate also depends on the efficiency (or rates) of biomass conversion into heat and power by the technological processes. For example, the net electricity production can be estimated by:

$$
\begin{array}{r}
F_{e l}=A_{h}\left(\sum_{s} F_{\text {harvest }, s} y_{s o f t, s} k_{\text {biogas }} H_{\text {biogas }} \eta_{e l}^{\text {biogas }}\right. \\
\left.+\sum_{s} F_{\text {harvest }, s}\left(1-y_{s o f t, s}\right) H_{w b} \eta_{e l}^{w b}\right)
\end{array}
$$

428 where $A_{h}$ is the harvested heathland area, $y_{s o f t, s}$ is the soft fraction in the biomass from species $429 \mathrm{~s}, k_{\text {biogas }}$ is the biogas yield from the input biomass flow, $H_{\text {biogas }}$ is the heating value of the 430 biogas produced from anaerobic digestion (AD), $\eta_{e l}^{\text {biogas }}$ is the electrical efficiency of the 431 combined heat and power (CHP) plant using biogas, $H_{w b}$ is the heating value of the woody 432 biomass and $\eta_{e l}^{w b}$ is the electrical efficiency of the CHP plant using woody biomass. A similar 433 equation can be obtained for heat production by replacing electrical efficiencies with thermal 434 efficiencies. The demand satisfaction indicator can be calculated by: 


$$
\delta_{e}=\frac{F_{e}}{D_{e}} \times 100
$$

435

436

437

where $\delta_{e}$ is the demand satisfaction percentage, $F_{e}$ is the energy supplied from the bioenergy production system and $D_{e}$ is the demand of reference which can be the total demand of the locality, or the demand from a particular subsystem such as the industrial component.

Another indicator of the ecosystem is the level of carbon capture by the heathland ecosystem (in both soil and biomass). This state indicator can be calculated by solving the following equation:

$$
\frac{d C_{(s+b)}}{d t}=\sum_{s}\left(\frac{F_{\text {growth }, s}}{f_{A G, s}}+M_{s}\right) y_{C}-C_{\text {soil }} k_{\text {loss } C}
$$

where $C_{(s+b)}$ is the total carbon capture rate by the heathland ecosystem in the soil and biomass prior to harvesting, $f_{A G, S}$ is the fraction of biomass growth allocated to above-ground biomass of species s. Thus $\frac{F_{\text {growth }, s}}{f_{A G, S}}$ is the total net growth, including both above-ground and below-ground biomass (Martinez-Hernandez et al. 2015). $M_{S}$ is the mortality rate of species s. $y_{C}$ is the carbon fraction in the biomass. $C_{\text {soil }}$ is the carbon stock in soil and $k_{\text {lossC }}$ is the soil C loss rate constant. Due to data limitations, carbon emissions from the biomass harvesting process are not included.

\section{<heading level 2> Quantitative analysis, results and discussion}

The model equations were solved for annual biomass harvesting of 1600 ha of heathlands around the Whitehill and Bordon eco-town for a period of $50 \mathrm{yr}$. The local atmospheric nitrogen deposition is $16 \mathrm{~kg} \mathrm{ha}^{-1} \mathrm{yr}^{-1}$. Model parameters and other inputs are reported elsewhere (Martinez-Hernandez et al. 2015). 
455 (in terms of cut fraction), the rate of nitrogen recycling, and the options for biomass

456 conversion:

457 1) CHP production via direct combustion of the whole harvested biomass

458 2) AD of soft biomass and using the biogas and woody biomass for CHP production

459 3) AD of sewage sludge to produce more biogas for CHP in addition to components in option 4602.

Note that only options 2 and 3 allow nitrogen recycling. The nitrogen that is recycled is the nitrogen originally present in the soft biomass that is recovered in the digestate resulting 463 from AD.

The objective of this case study is to assess (i) how much biomass we can harvest while maintaining the ecosystem and (ii) the effect of symbiotic integration, as given by the biomass harvest and the nitrogen recycling. Figure 6a shows how both cut fraction and $\mathrm{N}$ recycle ratio

467 affect the standing biomass in the heathland. Limited removal of heather biomass leads to a 468 longer term decline in heather biomass. This is because insufficient removal of heather biomass allows nitrogen to accumulate in the soil, which in turn allows grass to gain an advantage and eventually replace heather (converting heathland into a grassland). However, it was found that a cut fraction of 0.6 or higher depletes the system faster than it can recover and both heather and grass biomass decline continuously. The nitrogen recycling via the digestate proves to be beneficial as it increases biomass yield. However, the influence of cut fraction with nitrogen recycling is similar to the system without nitrogen recycling. Figure $6 \mathrm{~b}$ shows heather biomass that can be harvested and the nitrogen in soil at steady states for different cut fractions and 50\% nitrogen recycle. Cumulative harvested biomass is also shown. If the steady-state performance 
477 is used as the criterion, a cut fraction of 0.5 optimizes the system as the yield is the highest and 478 the nitrogen in soil is the lowest, thus achieving symbiosis between ecological and 479 technological processes. If only the cumulative biomass production over the considered 50 480 years is considered, a cut fraction of 0.4 provides best results, however at the expense of higher 481 nitrogen in soil, which may undermine the stability of the ecosystem.

Another indicator of interest for this case study was the level of carbon capture in the 483 ecosystem. Figure 6c shows the performance in terms of carbon captured in heathland (soil and 484 biomass) after 50 years management under different regimes of cut fraction and $\mathrm{N}$ recycle. For 485 low $\mathrm{N}$ recycles the carbon capture peaks at cut fraction of around 0.3 , which is when heather 486 starts becoming predominant. But at 95\% N recycle the carbon capture peaks at higher cut 487 fraction of 0.4 . It can be observed that at cut fractions of 0.4 and beyond, the fertilization by $\mathrm{N}$ 488 recycle from the energy production component increases the carbon captured in the heathland. 489 However, it should be noted that the desirable high carbon captured comes at the expense of 490 high accumulation of $\mathrm{N}$ in soil which can be detrimental for the ecosystem (Martinez$491 \quad$ Hernandez et al. 2015). 


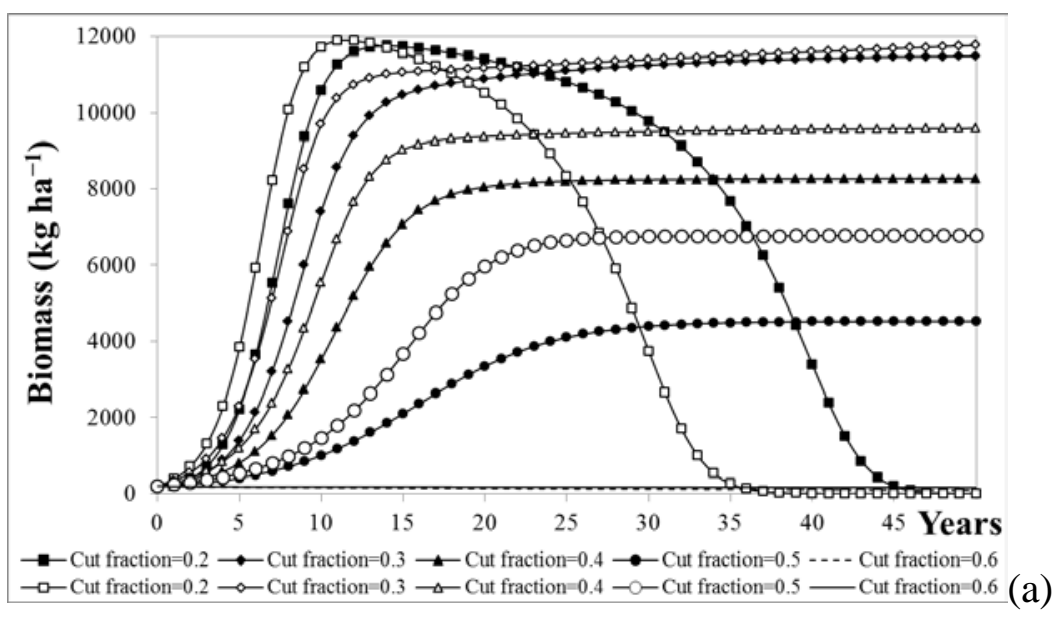

493

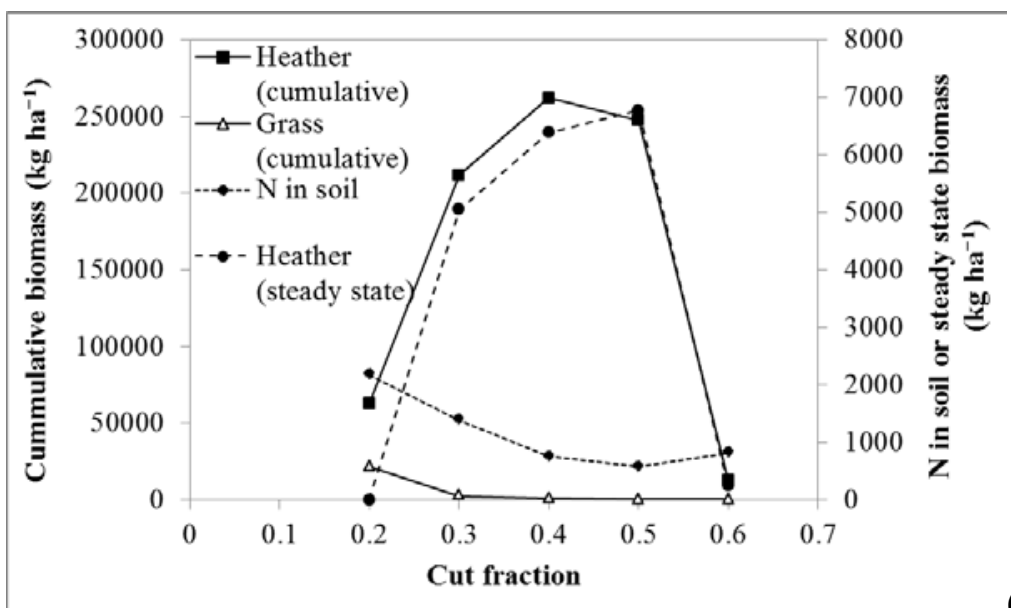

(b)

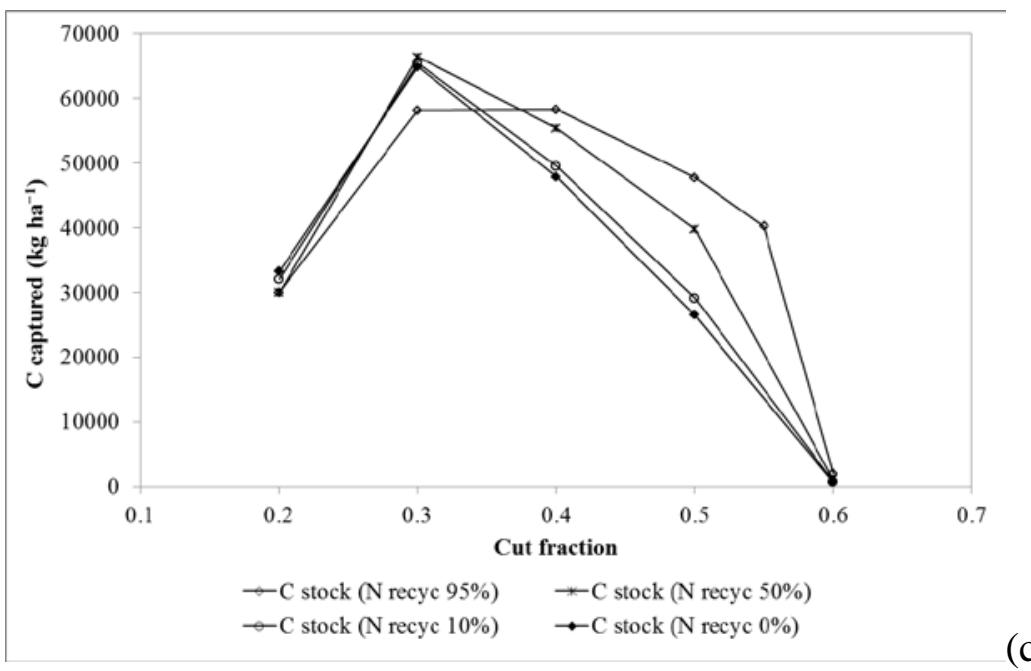

495 Figure 6. a) Dynamic trends of standing heather biomass under varying cut fractions and no 496 nitrogen recycle from soft biomass (filled markers) and with 50\% recycle (open markers); b)

497 harvested biomass at steady state, cumulative harvested biomass and nitrogen in soil after 50 
years management and 50\% nitrogen recycle, and c) cumulative carbon captured in the soil and biomass after 50 years management and 50\% nitrogen recycle.

Following the above analyses, the indicator for the percentage of energy that can be supplied to the eco-town whilst maintaining the health of the heathland can be evaluated. Using a cut fraction of 0.5 and recycling $50 \%$ of the nitrogen in soft biomass, the system's biomass resources at steady state were estimated. The three bioenergy and water treatment design options, outlined earlier in this section, were compared in terms of percentage of demand supplied, energetic efficiency, nitrogen emissions and digestate exported as fertilizer, as shown in figure 7. Whilst Options 2 and 3 can supply higher amounts of the total electricity and industrial heat demands of the eco-town, Option 1 is better in terms of efficiency in energy conversion. However, the nitrogen emissions (which could increase nitrogen deposition in the local ecosystem) are higher in Option 1. Furthermore, Options 2 and 3 allow the recovery of nutrients thus producing significant amounts of fertilizer for agricultural production. This could

511 also be integrated locally or exported to another local production system. Final decision requires an economic analysis, consideration of environmental policies as well as the criteria of the decision makers. Furthermore, consideration of the whole life cycle and all significant

514 carbon flows and environmental impacts well deserves further research so as to ensure that

515 decisions made to enhance interactions with ecological systems at the local scale, do not have 516 compromising implications at another stage in the life cycle and possibly at larger scales. In 517 fact, the cumulative resource consumption of each flow that enters a local production system has been considered in a separate work (Leung Pah Hang et al. 2014; Leung Pah Hang et al. 2015). Besides, methodological frameworks have been presented by Hanes and Bakshi (2015) and Bakshi et al. (2015), which address analyses across multiple scales. The framework shown

521 in the present paper complements these broader studies by providing the necessary detail on local techno-ecological interactions which can then be analyzed in the bigger picture. 
523

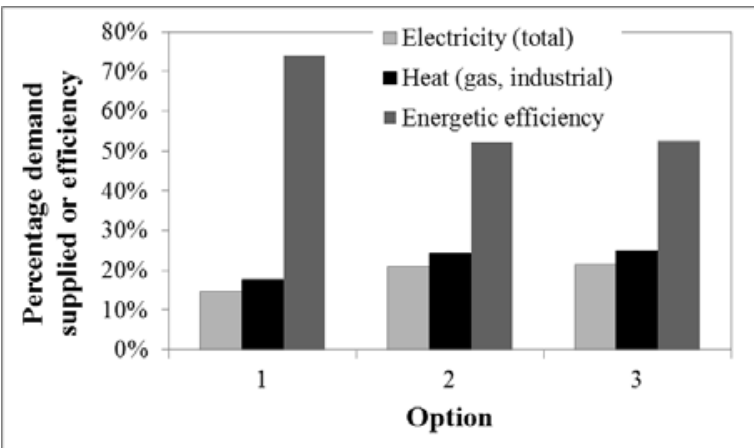

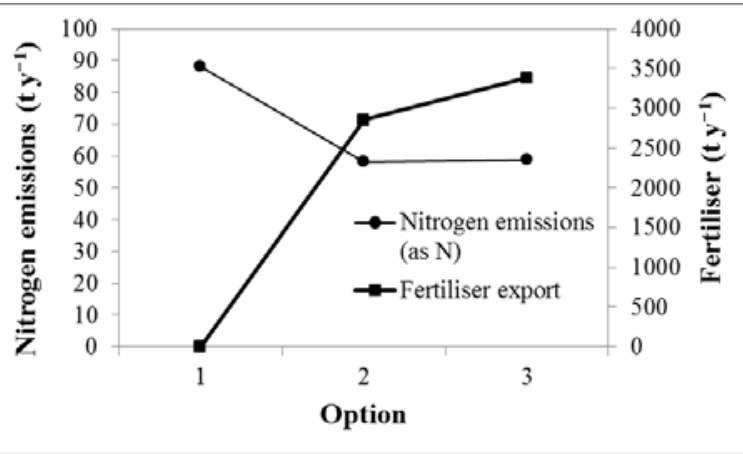

524 Figure 7. a) Percentage of demand that can be supplied by the three options for the local energy

525

526

production system analyzed; and b) Nitrogen emissions and fertilizer exported by the various options.

The case study effectively shows how the framework encourages exploration of the interactions between the ecological and technological processes, asking: which interactions can potentially enable a symbiotic connection? Which supporting states need to be taken care of in order to maintain the provisioning of resources such as biomass? Which processes affect such states and the flow of the resource of interest? These are key questions that help to conceptualize and devise options for symbiotic local production systems with technoecological interactions. This kind of interaction was also the focus of the development of a flow matchmaker for eco-industrial parks and remote exchange of flows at regional or national levels (Brown et al. 1997).

\section{$<$ heading level 1 $>$ Conclusions}

The system modeling framework proposed in this article, comprising a high-level conceptual model, a generic mathematical model, and generic procedures for constructing conceptual and mathematical models for localized production systems, was shown to be useful for devising options for a local energy production system which integrates both ecological and technological processes in a symbiotic way. The presented case study demonstrated how the framework can be applied to assess various design and operational 
543 options concerning the interactions between a heathland ecosystem, bioenergy production

544 and wastewater treatment. By explicitly analyzing the two-way connections between the

545 technical and ecosystem components, the framework also provided insight into the output of

546 the energy production system and the corresponding level of the ecosystem states critical for

547 the continuous provisioning of resources. The study of interconnected production,

548 consumption and waste treatment components interacting within a local production system,

549 with conscious integration with the relevant ecosystem components, could help to devise

550 future systems that contribute to the sustainable development of local areas, whether small

551 towns, villages, cities or regions. This means expanding the system boundary from that of

552 production systems alone - a limitation that work in certain areas of industrial ecology such

553 as the development of eco-industrial parks has the potential to overcome - to that of a broader

554 techno-ecological system, and revealing complex interactions between different types of

555 system components. It is envisaged that the framework presented here can be implemented in

556 a decision support software system for scenario building and optimization towards

557 sustainable local systems of production and consumption.

$558<$ heading level 1> Acknowledgments

559 Financial support from the Leverhulme Trust is greatly acknowledged.

$560<$ heading level $1>$ References

561 Bakema, A. H., R. Meijers, R. Aerts, F. Berendse and G. W. Heil. 1994. HEATHSOL: A

562 Heathland Competition Model. Netherlands National Institute for Public Health and the

563 Environment (RIVM).

564 Bakshi, B. R., G. Ziv, M. D. Lepech. 2015. Techno-Ecological Synergy: A Framework for

$565 \quad$ Sustainable Engineering. Environmental Science and Technology 49: 1752-1760. 
566 Brown, J., D. Gross, and L. Wiggs (1997). The MatchMaker! System: Creating Virtual Eco-

567 Industrial Parks. In: Chertow M. (2002). Developing Industrial Ecosystems: Approaches, $568 \quad$ Cases, and Tools. Yale F\&ES Bulletin 106.

569 Chertow M. and J. Ehrenfeld. 2012. Organizing self-organizing systems. Toward a theory of industrial symbiosis. Journal of Industrial Ecology 16(1): 13-27.

571 Curtis, F. 2003. Eco-localism and sustainability. Ecological Economics 46: 83-102.

572 Desrochers, P. 2001. Cities and Industrial Symbiosis: Some Historical Perspectives and 573 Policy Implications. Journal of Industrial Ecology 5(4): 29-44.

574 Eckelman M. J., W. Ashton, Y. Arakaki, K. Hanaki, S. Nagashima and L.C. Malone-Lee. 575 2014. Island waste management systems. Statistics, challenges, and opportunities for 576 applied industrial ecology. Journal of Industrial Ecology 18(2): 306-317.

577 Fröhling M., F. Schwaderer, H. Bartusch and F. Schultmann, 2013. A material flow-based approach to enhance resource efficiency in production and recycling networks. Journal of Industrial Ecology 17(1): 5-19.

Hanes, R. J., and B. R. Bakshi. 2015a. Process to planet: A multiscale modeling framework toward sustainable engineering. AIChE Journal 61(10): 3332-3352.

582 Hardy, C. and T. E. Graedel. 2002. Industrial ecosystems as food webs. Journal of Industrial $583 \quad$ Ecology 6(1): 29-38.

584 Heil, G.W. and R. Bobbink. 1993. CALLUNA a simulation model for evaluation of impacts 585 of atmospheric nitrogen deposition on dry heathlands. Ecological Modelling 68(3-4): $586 \quad 161-182$. 
Hiete M., J. Ludwig and F. Schultmann. 2012. Intercompany energy integration. Adaptation of thermal pinch analysis and allocation of savings. Journal of Industrial Ecology 16(5): 689-698.

Jacobsen, N. B. 2006. Industrial symbiosis in Kalundborg, Denmark: a quantitative assessment of economic and environmental aspects. Journal of industrial ecology, 10(1-2): 239-255.

Johansson, A., P. Kisch and M. Mirata. 2005. Distributed economies - A new engine for innovation. Journal of Cleaner Production, 13, 971-979.

Korhonen, J. 2004. Industrial ecology in the strategic sustainable development model: strategic applications of industrial ecology. Journal of Cleaner Production 12(8-10): 809823.

Kröner, A., P. Holl, W. Marquardt and E. D. Gilles. 1990. DIVA-an open architecture for dynamic simulation. Computers and chemical engineering 14(11): 1289-1295.

Layton, A., B. Bras, and M. Weissburg. 2015. Industrial Ecosystems and Food Webs: An Expansion and Update of Existing Data for Eco-Industrial Parks and Understanding the Ecological Food Webs They Wish to Mimic. Journal of Industrial Ecology, Online Version of Record, DOI: 10.1111/jiec.12283.

Layton, A., J. Reap, B. Bras, and M. Weissburg. 2012. Correlation between thermodynamic efficiency and ecological cyclicity for thermodynamic power cycles. PLoS ONE 7: 51841.

Leung Pah Hang M.Y., E. Martinez-Hernandez,, Leach M., Yang, A. 2014. A multi-level framework for resource accounting, 17th European Roundtable on Sustainable Consumption and Production, 14-16 October 2014, Portoroz, Slovenia. 
609 Leung Pah Hang, M.Y., Martinez-Hernandez, E., Leach, M., Yang, A. 2015. Engineering

610 Design of Localised Synergistic Production Systems, Computer Aided Chemical

$611 \quad$ Engineering 37: 2363-2368.

612 Liang, S., L. Shi and T. Zhang. 2011. Achieving dewaterization in industrial parks. A case

613 study of the Yixing economic development zone. Journal of Industrial Ecology 15(4):

614 597-613.

615 Martinez-Hernandez, E., M. Leach and A. Yang. 2015. Impact of bioenergy production on

616 ecosystem dynamics and services - A case study on heathlands. Environmental Science and

617 Technology 49(9): 5805-5812.

618 Mattila, T., S. Lehtoranta, L. Sokka, M. Melanen and A. Nissinen. 2012. Methodological

619 aspects of applying life cycle assessment to industrial symbioses. Journal of Industrial

$620 \quad$ Ecology 16(1): 51-60.

621 MEA (Millennium Ecosystem Assessment). 2005. Ecosystems and human wellbeing:

622 synthesis. Island Press, Washington DC.

623 Morbach, J., A. Yang and W. Marquardt. 2007. OntoCAPE-A large-scale ontology for

624 chemical process engineering. Engineering Applications of Artificial Intelligence, 20 (2):

$625 \quad 147-161$.

626 Power, S.A., C. G. Barker, E. A. Allchin, M. R. Ashmore and J.N.B. Bell. 2001. Habitat

627 management: a tool to modify ecosystem impacts of nitrogen deposition? Scientific World

$628 \quad 1: 714-721$.

629 Power, S.A.; Ashmore, M.R.; Terry, A.C.; Caporn, S.J.M.; Pilkington, M.G.; Wilson, D.B.;

630 Barker, C.G.; Carroll, J.A.; Cresswell, N.; Green, E.R.; Heil, G.W. Linking field 

experiments to long-term simulation of impacts of nitrogen deposition on heathlands and moorlands. Water Air Soil Poll. 2004, 4 259-267.

633 RAE (Royal Academy of Engineering). 2011. Infrastructure, Engineering and Climate Change Adaptation -ensuring services in an uncertain future. ISBN 1-903496-61-6

635 Rumbaugh, J., I. Jacobson and G. Booch. 2004. Unified Modeling Language Reference 636 Manual. US: Pearson Higher Education.

637 Song, X. and B. Frostell. 2012. The DPSIR Framework and a Pressure-Oriented Water 638 Quality Monitoring Approach to Ecological River Restoration. Water 4: 700-712.

639 Urban, R.A. and B. R. Bakshi. 2013, Techno-Ecological Synergy as a Path Toward 640 Sustainability of a North American Residential System. Environmental Science and 641 Technology 47(4): 1985-1993.

642 Urban, R.A., B.R. Bakshi, G.F. Grubb, A. Baral, W.J. Mitsch. 2010. Towards sustainability 643 of engineered processes: Designing self-reliant networks of technological-ecological $644 \quad$ systems. Computers and Chemical Engineering, 34(9):1413-1420.

645 Whitehill and Bordon. 2012. Eco-town Masterplan. Hampshire, UK.

646 Woodcock, M. and P. Stephens. 2012. Potential biomass supply from local heathlands for 647 energy. Forestry Commission, UK.

648 Worrall, F. and G. D. Clay. 2014. The potential use of heather, Calluna vulgaris, as a 649 bioenergy crop. Biomass and Bioenergy 64: 140-151.

\section{$<$ heading level $1>$ About the authors}

651 Elias Martinez-Hernandez is a Research Fellow and Aidong Yang is an Associate Professor, both working at the Department of Engineering Science of the University of Oxford in the 
653 UK. Melissa Yuling Leung Pah Hang is a PhD research student and Matthew Leach is a

654 Professor of Energy and Environmental Systems, both working at the Centre for

655 Environmental Strategy, University of Surrey in the UK. 